\title{
Лексико-семантическое поле «движение вперед» в англоязычном деловом дискурсе
}

\author{
Мадинян Е.И. \\ Российский университет дружбы народов, \\ Россия, 117198, г. Москва, ул. Миклухо-Маклая, д. 6 \\ E-mail: madinyan-ei@rudn.ru
}

\begin{abstract}
Аннотация. Важную роль в ходе деловых переговоров англоязычных компаний играют коллокации, так как позволяют лаконично и четко передавать информацию. В научной литературе коллокации лексико-семантического поля «движение вперед» рассматриваются, как правило, с точки зрения комбинаторных, синтаксических и лексико-семантических признаков. Однако остается малоизученной их роль в лингвопрагматическом аспекте, в частности в сфере деловых отношений. Целью данного исследования является изучение лексико-семантических и лингвопрагматических аспектов коллокаций, включающих в себя семантику лексических единиц и особенности их функционирования в деловом дискурсе. В статье используются методы сплошной выборки, систематизации, интерпретации, а также лексико-семантический и лингвопрагматический анализ. Особое внимание уделяется изучению функций, выполняемых коллокациями в деловом дискурсе. Выявлено четыре наиболее распространенных микрополя, составляющих лексико-семантическое поле «движение вперед»: микрополе «идти», микрополе «подъем», микрополе «движение вперед с элементами игры» и микрополе «движение вперед с применением грубой силы». Систематизация коллокаций в рамках микрополей позволяет провести более детальный семантический анализ с учетом семантического выражения коллокаций исследуемого лексико-семантического поля. Главными функциями коллокаций, входящих в ЛСП «движение вперед», являются информативная, экспрессивная, апеллятивная и оценочная. Также была выявлена тенденция к выполнению коллокациями одновременно нескольких функций в деловом дискурсе. Полученные результаты вносят вклад в развитие теории лексикосемантического поля и лингвопрагматики.
\end{abstract}

Ключевые слова: коллокации, лексико-семантическое поле, лингвопрагматика, деловой дискурс

Для цитирования: Мадинян Е.И. 2021. Лексико-семантическое поле «движение вперед» в англоязычном деловом дискурсе. Вопросы журналистики, педагогики и языкознания, 40 (4): 520 533. DOI: $10.52575 / 2712-7451-2021-40-4-520-533$

\section{Lexical-Semantic Field "Moving Forward" in English Business Discourse}

\author{
Elena I. Madinyan \\ Peoples' Friendship University of Russia, \\ 6 Miklukho-Maklaya St, Moscow 117198, Russian Federation \\ E-mail: madinyan-ei@ rudn.ru
}

\begin{abstract}
Collocations play an important role during meetings and business negotiations of Englishspeaking companies, as they allow you to convey information concisely and clearly. In the scientific literature, collocations of the lexico-semantic field "moving forward" are observed from the standpoint of combinatorial, syntactic and lexico-semantic features. However, their role in the linguopragmatic aspect is poorly studied, in the field of business relations in particular. The purpose of this research is to study the lexical-semantic and linguopragmatic aspects of collocations, including the semantics of lexical units and the features of their functioning in business discourse. There are the following methods employed in
\end{abstract}


the article: continuous sampling, systematization, interpretation, as well as lexical-semantic and linguopragmatic analysis. Special attention is paid to the study of the functions performed by the collocations in business discourse. The four most common microfields that constitute the lexico-semantic field "moving forward" have been identified: the microfield "to go", the microfield "rise", the microfield "moving forward with elements of the game" and the microfield "moving forward with the use of brute force". Systematization of collocations within microfields allows for a more detailed semantic analysis taking into account the semantic expression of collocations of the lexical-semantic field under study. The main functions of collocations included in lexical-semantic field "moving forward" are informative, expressive, appellative and evaluative. There is also a tendency for collocations to perform several functions simultaneously in business discourse. The theoretical and practical significance of the article lies in the fact that it contributes to the field of lexical semantics and linguopragmatics and its results can be reflected in collocation dictionaries, as well as in teaching English to students and while conducting corporate English trainings. The obtained results contribute to the development of the theory of lexicosemantic field and linguopragmatics.

Keywords: collocations, lexico-semantic field, linguopragmatics, business discourse

For citation: Madinyan E.I. 2021. Lexical-Semantic Field "Moving Forward" in English Business Discourse. Issues in Journalism, Education, Linguistics, 40 (4): 520-533 (in Russian). DOI: $10.52575 / 2712-7451-2021-40-4-520-533$

\section{Введение}

За последние 20 лет исследование семантических отношений и групп слов в лексических и лексико-семантических системах языка значительно продвинулось: изучается понятие лексической и лексико-семантической парадигмы, используется метод оппозиций для определения признаков лексических значений слов и др. [Томалин, Малюга, 2016; Sibul, 2017; Peluso, 2021]. Системный подход в лингвистике основан на связях слов, таких как лексико-семантические поля и лексико-семантические группы.

В данной работе предлагается способ исследования коллокаций в деловом дискурсе, основанный на применении теории лексико-семантического поля (ЛСП), которая способствует раскрытию внутренней языковой системы. Теория поля актуализирует проблемы лексико-семантических полей, затрагивающие их структурную иерархию и типологию.

Впервые термин «лексико-семантическое поле» был использован исследователями Х. Ибсеном [1924] и Й. Триром [1931] в ХХ веке. Большой вклад в дальнейшее развитие теории лексико-семантического поля был сделан В. Порцигом [1934], Ю.Д. Апресяном [1974], Г.С. Щуром [1974], З.Д. Поповой [2010], Л. Бринтон [2000], О.Е. Потаповой [2020] и др. В данных исследованиях особое внимание уделялось парадигматической категории. Согласно этой теории, значение лексемы не может быть объективно описано без учета значений лексических единиц одного лексико-семантического поля. Различные лексикосемантические связи оказывают влияние на отношения между словами.

В рамках лексико-семантических полей ученые анализируют комбинаторные, синтаксические и лексико-семантические признаки коллокаций. Однако остается пока малоизученной их роль в лингвопрагматическом аспекте в частности в сфере деловых отношений, что обуславливает актуальность данного исследования.

Целью данного исследования является изучение лексико-семантических и лингвопрагматических характеристик коллокаций в рамках ЛСП «движение вперед» в британском деловом дискурсе, а именно описание их семантического выражения, выявление функций и лингво-прагматических интенций.

Материалом для настоящего исследования послужили транскрипты переговоров таких британских компаний как Unilever, British Petroleum, HSBC. Объектом исследования являются коллокации, относящиеся к лексико-семантическому полю «движение вперед». Всего было выделено 800 глагольных коллокаций. Применяется лингвопрагматический 
подход для изучения закономерности отбора языковых средств в определенной ситуации общения и последующего влияния этого выбора на реципиентов [Crystal, 2010, c. 240; Maлев, Масалова, 2013, с. 116; Laura Alba-Juez, 2018].

\section{Структура лексико-семантического поля}

Лексико-семантическое поле (ЛСП) включает в себя такие явления, как синонимия, антонимия, полисемия, соотношение слова и понятия. Однако наиболее комплексным является семантическое поле, которое представляет собой иерархическую организацию слов, объединенную одним родовым значением и представляющую в языке определенную семантическую сферу, покрывающую определенную область действительности [Тамбовцева, 2014, с. 142].

В рамках семантического поля И.В. Сентенберг выделяет следующие иерархические связи: лексико-семантические поля; лексико-семантические группы; тематические ряды (лексико-семантические подгруппы); многозначные слова, синонимические ряды, антонимические ряды, конверсивы [Сентенберг, 1984, с. 56]. Мы видим, что лексикосемантическое поле - это одна из составляющих иерархии, в которой она занимает первое место. В исследованиях многих ученых [К.Д. Тамбовцева, 2014; Н.С. Белякова, 2017] используется термин «микрополе» при выделении более узких тематических групп лексикосемантических полей. Например, в лексико-семантическом поле International trade relations можно выделить следующие микрополя: trade, tariffs, trade barriers, trade regulations and trade policies [Белякова, 2017].

За лексико-семантическим микрополем следует лексико-семантическая группа (ЛСГ), которая является частью лексико-семантической системы языка и объединяет значения близких по смыслу слов одной и той же части речи на основе неотъемлемых семантических признаков как обязательного компонента. С другой стороны, она очень близка синонимическому ряду, так как она представляет собой связку синонимов для основного значения доминанты.

Согласно 3.Д. Поповой и И.А. Стернину [2010] в структуре ЛСП может быть также выделено ядро, ближняя и дальняя периферии значения. К ядру относятся основные, постоянные, эксплицитные семы, к периферии - неосновные и вероятностные семы. Ядерными могут быть как денотативные, так и коннотативные семы. Ядерные семы являются основой различных лексических группировок в системе языка, именно они являются основой для построения парадигм, синонимических рядов, антонимических пар, лексикосемантических и тематических групп. Функциональные семы обычно входят в периферию. Периферийные семы обозначают менее существенные, непостоянные признаки предмета, не являющиеся для предмета основными. Актуализируясь в речи, периферийные семы создают образность и экспрессивность лексической единицы или коллокации, выступают основой образования переносных значений, расширяют номинативные возможности лексемы. Данные семы могут быть очень яркими и их реализация в основном обусловлена метафорическим переносом значения, например, использование dough в значении слова топеу и др.

Е.Н. Малюга [Maluyga, Aleksandrova, 2020. с. 2] в работе "Linguopragmatic aspect of idiomatic expressions in English business discourse" выделяет пять наиболее частотных семантических групп, используемых в англоязычном деловом дискурсе:

1) группа, в которой деловые процессы наделяются свойствами людей;

2) группа, в которой деловые отношения сравниваются с супружескими;

3) группа, указывающая на схожесть деловых процессов с особенностями ведения военных действий;

4) группа процесса нахождения в пути, движения вперед;

5) группа, проводящая параллель с деятельностью по выслеживанию и добыче чего-либо. 
Все вышеупомянутые семантические группы обладают ярким образным планом и выраженным прагматическим эффектом, который играет важную роль в деловом дискурсе [Malyuga, McCarthy, 2018; Kuzhevskaya, 2019; Малюга, 2020].

Данные семантические группы также находят отражение в британском деловом дискурсе, однако наибольший интерес для настоящего исследования представляет лексико-семантическое поле «движения вперед, нахождения в пути», так как, во-первых, при изучении материала исследования было обнаружено, что данное поле состоит из наибольшего количества примеров, во-вторых, для делового дискурса оно имеет существенное значение, так как, передает не только значения передвижения и перемещения, но значения материального благополучия бизнеса, компании или человека (возглавлять, идти на повышение, продвигаться по службе, подниматься в цене, расти, улучшаться и т.д.).

Общая сема «движение вперед» является ядром данного лексико-семантического поля и, изучив исследуемые транскрипты, мы выявили, что ядро ЛСП глаголов движения в английском языке составляет лексема move; ближняя периферия представлена такими лексемами, как drive, go, walk, come, step, follow, run, stroll, track; дальняя периферия включает в себя большее количество лексем: crawl, stray, lead, climb, fly, carry, extend, drag, seek, pass, navigate, get, give, deliver, jump, accelerate, top, unwind, spin, pivot, surge, bounce, grapple, plug, strike, chop, hit, pinch on, squeeze in, smash, sweep, embark on, push, grab, roll, skew in, turn, head, pave, leverage, scale up, lift, ramp up, tweak, look for, enter, flow, kick in. Данный факт объясняется тем, что, согласно Е.А. Митиной, языковые единицы, расположенные на периферии, обладают более сложным, насыщенным, специализированным содержанием и тесно взаимодействуют с членами смежных полей. Следовательно, данные лексемы обладают большей стилистической выразительностью и эмфатичностью [Митина, 2010, с. 295].

В рамках ЛСП «движение вперед» мы выделяем следующие микрополя: «идти», «подъем», «движение вперед с элементами игры» и «движение вперед с применением грубой силы» (см. рисунок).

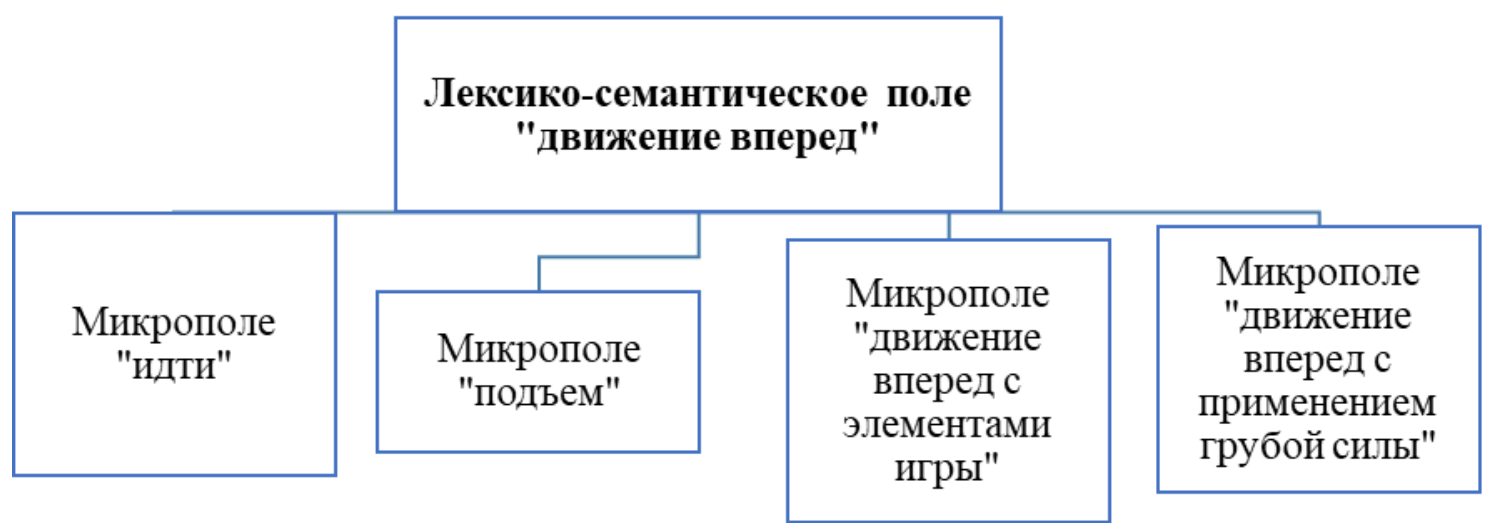

Лексико-семантическая структура ЛСП «движение вперед»

Lexico-semantic structure of the LSP "moving forward"

Дробление ЛСП на микрополя позволяет более полно систематизировать лексические единицы с учетом семантических признаков, а также способствует пониманию смысла и лингвопрагматического значения коллокаций. Общей характеристикой лексических единиц, входящих в вышеуказанные микрополя в деловом дискурсе, является направленность движения вперед, в остальном их лексико-семантические свойства варьируются. Детальное описание коллокаций, входящих в указанные микрополя, с их лингвопрагматическими характеристиками представлено в следующем разделе. 


\section{Лингвопрагматические характеристики коллокаций, входящих в лексико-семантическое поле «движение вперед»}

Коллокации представляют особый интерес для нашего исследования, так как они воспринимаются как неотьемлемая часть лексического запаса и посредством частого и повторяющегося употребления становятся конвенциональными, приобретают устойчивое, предметно-специфическое значение и определенные культурные коннотации.

Вслед за А.Н. Барановым и Д.О. Добровольским, под коллокациями мы понимаем слабоидиоматичные фразеологизмы преимущественно со структурой словосочетания, в которых семантически главный компонент (база) употреблен в своем прямом значении, а сочетаемость со вспомогательным компонентом (коллокатом) может быть задана в терминах семантического класса, но выбор конкретного слова всегда предопределен узусом [Баранов, Добровольский, 2013, с. 73].

Охарактеризуем материал исследования через призму лингвопрагматики, то есть, во-первых, обозначим общественно-статусные параметры адресанта и адресата. Unilever является крупной международной компанией, производящей пищевые продукты и бытовую химию, British Petroleum - это транснациональная нефтегазовая компания и, наконец, HSBC - это крупнейший банк Великобритании. Эти организации имеют международное признание, являются сильными конкурентами на мировом рынке и оказывают существенное влияние на состояние рынка. Их целевую аудиторию во время совещаний составляют инвесторы, акционеры, потребители со всего мира и многие другие.

Также необходимо отметить условия и цели речевых актов. Нами были рассмотрены примеры из транскриптов совещаний и переговоров, доступных онлайн. Цель данных транскриптов заключается в том, чтобы донести информацию, связанную с текущим положений компаний на рынке, а также их планами и стратегиями до аудитории, включающей потенциальных инвесторов, экономистов, маркетологов, акционеров и других заинтересованных лиц.

Детальное ознакомление с исследуемыми транскриптами позволило выделить их четыре ключевые особенности:

1. Ясность и однозначность сообщения, отсутствие двусмысленности.

2. Особая важность информативной функции.

3. Использование языковых средств с целью привлечения внимания целевой аудитории к тому или иному явлению.

4. Ориентир на принятие решения и, в зависимости от цели совещания, определение будущих стратегий и траекторий.

Несмотря на исключительно деловой формат совещаний, в данном исследовании мы также выявили редкие случаи употребления слов развлекательной функции, которая указывает на необходимость внедрения ice breakers в процесс переговоров с целью разрядить обстановку и расположить к себе участников. Рассмотрим следующий пример:

We do think the results were decent. It was another good quarter for Markets, but I would just foreshadow, our General Manager thinks there is a progressive reverting to normalization. He gave a great 10-minute business speech on this topic at our last meeting. The only problem was it took him half an hour to deliver it. So let's state it briefly. - Mbl действительно считаем, что результаты были хорочими. Это был еще один положительный квартал для рынков, но я бы хотел предупредить, что наш генеральный менеджер считает, что происходит постепенный возврат к нормализачии. На нашей последней встрече он произнес великолепную 10-минутную деловую речь на эту тему. Единственная проблема заключалась в том, что ему потребовалось полчаса, чтобы завершить ее. Поэтому давайте изложим это вкратцер.

\footnotetext{
1 Здесь и далее перевод автора.
} 
В данном примере развлекательная функция заключается в шутке He gave a great 10-minute business speech on this topic at our last meeting. The only problem was it took him half an hour to deliver it. Здесь мы можем наблюдать такие глаголы движения с компонентом «вперед», как give и deliver, благодаря которым и достигается юмористический эффект. Коллокация to give speech, имеющая значение «выступать, произносить речь», делает больший акцент на процесс произношения речи, хотя и может иметь значение завершенности при употреблении в прошедшем времени. Следовательно, аудитория приходит к выводу, что речь была уже завершена, пока не услышит/прочитает коллокацию to deliver speech, которая обладает прямым значением завершения чего-либо, достижения конечного пункта. Помимо вышеописанной развлекательной функции, в данном отрезке также имеется эмфатическая конструкция we do think..., используемая с целью подчеркнуть тот факт, что говорящий не только высказывает общее мнение, а и то, что он полностью уверен в нем. Мы не относим коллокации to give speech и to deliver speech ни к одному из выделенных микрополей в связи с их уникальными для ЛСП «движение вперед» семантическими характеристиками и единичностью случаев употребления в данном ЛСП, что, однако, может способствовать дальнейшему выделению микрополя, к которому будут относится коллокации, обладающие уникальными семантическими характеристиками.

\section{Лексико-семантическое микрополе «идти»}

В деловой среде микрополе «идти» выражает целеустремленность компании и ориентацию на постепенное достижение своих целей. Глаголы move, walk, come, step и head указывают на движение компании по определенному пути. Данные глаголы символизируют единство изменчивости и устойчивости (при ведущей роли изменчивости) [Ваганова, 2018]. Устойчивость выражается в непрерывности движения, а изменчивость - в самом процессе движения. Стоит отметить, что, согласно С.Н. Медведевой, глаголы движения не выполняют смыслообразующую роль в составе коллокаций. Напротив, смыслообразующее ядро смещено в сторону коллокатов, в то время как глагол движения выполняет связывающую функцию, функцию предикации, что также подтверждается в нашем исследовании [Медведева, 2019, с. 37]. Вариативность глаголов движения позволяет им сочетаться с неограниченным количеством коллокатов, что свидетельствует об их гибкости и относительной устойчивости в языке.

Just a few quick introductory remarks from me and then we can move to $Q \& A$ pretty swiftly. Hopefully you picked up a more confident tone from Noel and I at the $3 Q$ results announcement last week. - Всего несколько коротких вступительных замечаний от меня, а затем мы можем довольно быстро перейти к вопросам и ответам. Надеюсь, что Ноэль и я придали вам уверенности при объявлении результатов 3-го квартала на прошлой неделе.

Коллокация to move swiftly - «быстро перейти» имеет положительные коннотации и используется в данном отрывке с целью усилить сообщение о том, что вступительные замечания будут очень быстрыми. Данная коллокация широко распространена в деловом дискурсе, так как она имплицитно проводит параллель между совещанием и быстрым передвижением (пешком или с помощью транспортного средства), давая слушателям понять, что процесс должен быть «непрерывный» и «управляемый». Данный пример является обращением к аудитории, отражающим последовательность выполнения действий, содержащихся в повестке дня. Следовательно, в конкретном случае коллокация выполняет апеллятивную функцию.

Okay. Great. And just on costs, could you walk us through 2021 - it sounds like you're expecting a fairly linear decline to your new guidance down to 2021 and loose guidance to 2022. Is that the right way to think about it? - Хорошо. Отлично. А что касается затрат, не могли бы вы сделать нам обзор 2021 года - похоже, вы ожидаете довольно прямого снижения 
вамего нового руководства до 2021 года и ослабления руководства до 2022 года. Мои предположения верны?

Коллокация to walk through, выраженная глагольно-предложным сочетанием, отражает желание автора высказывания получить помощь при рассмотрении результатов компании. Такое специфическое слово, как walk отличается как от go, так и от run по своим семантическим характеристикам: «идти пешком / прогулка пешком» и является уникальным для английского языка. Метафорическая проекция данной языковой единицы заключается в переходе коллокации walk through (npoxодить через) из сферы источника в сферу мишень, где данное выражение получило более абстрактное значение «проинструктировать, предоставить информацию». Данная метафора пробуждает у реципиента ассоциации с прохождением через какие-либо препятствия с оказанием со стороны компании всяческого содействия в их преодолении и выполняет экспрессивную и апеллятивную функции, поскольку является частью просьбы [Murashova, 2021].

The risks presented by the pandemic have not reduced and many experts are warning of the risks of a second wave. And while the search for a vaccine goes on, we will perhaps all need to be prepared to step forward and step back in the months ahead. - Риски, связаннье с пандемией, не снизились, и многие эксперты предупреждают о вероятности второй волныл. И пока идет поиск вакцины, возможно, нам всем придется быть готовыми к тому, что в ближайшие месяџы нам придется сделать шаг вперед и шаг назад.

На лексическом уровне коллокация to step forward употребляется с целью выразить готовность компании к положительному развитию в условиях сложившейся в мире экономической ситуации, в то время как противоположная по значению коллокация to step back отражает ее противоречивость и непостоянство и служит созданию антитезы. Наличие контраста обуславливает экспрессивную функцию коллокации и усиливает ее выразительность. Начало второго предложения с союза and и использование фразовых глаголов go on, step forward и step back характеризует неофициальный стиль высказывания, когда остальные лексические единицы относятся к официально-деловому.

And I was wondering whether the Board had a conversation around whether you should accelerate that further, in terms of a break-up of the business, so potentially closing the US and freeing up capital, spinning off the UK ring-fenced bank and just focusing more on the Asian businesses, which is where you seem to be heading anyway? Thanks. - И мне было интересно, вел ли Совет директоров разговор о том, следует ли вам ускорить этот процесс еще больше, с точки зрения распада бизнеса, следовательно, потенциально закрывая компании в США и освобождая капитал, открыть защищенный британский банк, и просто больше конщентрироваться на ведении бизнеса в азиатских странах, что, похоже, и является вашей траекторией? Спасибо.

Лексема to head является примером антропоморфизма. Благодаря соматической метафоре человек может структурировать свои знания о мире, перенося на него принципы устройства и функционирования своего собственного организма [Мартынова, 2008]. В деловом дискурсе сравнение экономических процессов с человеческим организмом осуществляется с целью внушить читателю или слушателю, что экономические процессы им близки и понятны, что в них действуют такие же законы. Будучи познавательной моделью, с помощью которой описывается и прогнозируется окружающий мир, метафора, используя ассоциации, имплицитным образом внедряет в сознание индивида определенные идеи, установки, желания или намерения, отличающиеся от тех, которые имеются у него на данный момент, следовательно, она заключает в себе довольно важный лингвопрагматический аспект. С синтаксической точки зрения, на локутивном уровне, данное предложение является косвенным, что, учитывая его специфику, представляет интерес для лингвопрагматического подхода. Согласно В.В. Дранко, применяя в вопросе не прямой, а косвенный порядок слов, адресант таким образом переводит вопрос из категории прямого речевого акта в категорию просьбы, следовательно, достигая большего прагматического эф- 
фекта на перлокутивном уровне, так как положительной является именно реакция на просьбы в силу вежливости высказывания. Данный эффект усиливается за счет добавления лексемы Thanks в конце высказывания, так как, заранее поблагодарив реципиента, адресант не оставил ему выбора, кроме как ответить на заданный вопрос [Дранко, 2006, с. 195]. Коллокация в данном примере выполняет экспрессивную и апеллятивную функции.

\section{Лексико-семантическое микрополе «подъем»}

Следующее микрополе, которое мы разберем более детально, - это микрополе «подъем». В данное микрополе входят глагольные, субстантивные и адьективные коллокации, указывающие на рост показателей компаний в исследуемых переговорах.

Commercial real estate is a new area that we've been applying ourselves to post-COVID. Pre-COVID, we would have thought that what we called desk-sharing ratios would have topped out at 1.4, i.e. you had one desk for every 1.4 people trying to use it. - Коммерческая недвижимость - это новая область, в которой мы пробуем себя после пандемии COVID. До COVID мы думали, что то, что мы называли коэффициентом разделения рабочих столов, должно было превысить показатель 1,4, то есть у вас был один стол на каждые 1,4 человека, пытающихся им воспользоваться.

В данном отрезке микрополе «подъем» вербализовано через коллокацию to top out, которая представлена фразовым глаголом и обозначает «достижение высшей точки/пика». Использование данной коллокации в значении «превышать» свидетельствует о временности данного показателя, так как семантический анализ фразового глагола показывает, что он используется, когда речь идет о неустойчивости ситуации и постоянной изменчивости показателей. Следовательно, целью автора является отметить неустойчивость упомянутого коэффициента. Употребление коллокации, указывающей на наивысшую отметку, обуславливает выполнение оценочной функции.

COVID-19 has definitely accelerated that shift to digital, and we're seeing, as a result, significant take-up on these platforms. And we also have got some good transformative stuff going on in the back office, like in my own area a project called Finance on the Cloud. - COVID19 определенно ускорил этот переход к цифрровым технологиям, в результате мы наблюдаем значительное задействование этих платформ. И у нас также происходят некоторые изменения в офисе, например, в моем собственном отделе запускается проект под названием Финансы в Облачном хранилище.

В данном примере мы наблюдаем коллокацию to accelerate shift, основным значением которой является «ускорить переход». Употребление глагола to accelerate делает акцент на прогрессивности бизнеса, изменчивости и постоянном стремлении идти вперед. Коллокация представляет собой олицетворение, так как исполнителем действия является Ковид-19, и выполняет экспрессивную функцию. В настоящем примере мы также выделяем коллокацию significant take-up - «значительное задействование», в которой существительное take-up образовано путем конверсии от фразового глагола to take up. Выбор данных лексических средств позволяет автору обратить внимание слушателя/читателя на то, что компания не стоит на месте и готова достигать вершин в освоении новых технологий в условиях нестабильной экономики.

\section{Лексико-семантическое микрополе «движение вперед с элементами игры»}

Коллокации, входящие в микрополе «движение вперед с элементами игры», формируют свое значение при помощи метафорического переноса. Многие исследователи, в том числе А.П. Чудинов и С.Р. Агабаян, отмечают важность использования образов соревнований и игр, таких как гонка, забег, марафон, именно в политическом дискурсе. Обсуждение серьезных политических проблем и голосование часто представляется в виде схватки бойцов, поединка боксеров, теннисного, футбольного или хоккейного матча. Ме- 
тафора отражает стратегию команды, работу группы поддержки, реакцию болельщиков, горечь поражения и радость победы [Чудинов, 2003, с. 95]. Согласно нашему исследованию, сфера политики - не единственная возможная сфера применения коллокаций, образованных при помощи игровых метафор. В англоязычных бизнес-транскриптах коллокации-метафоры, входящие в микрополе «движение вперед с элементами игры», также используются с целью соотношения элементов игры с деловыми процессами. Рассмотрим следующие примеры:

Market research showed that many companies are trying to take market share by playing catch uр... - Исследования рынка показали, что многие компании пытаются занять свою долю рынка, стремясь сравняться с конкурентами...

Коллокация to play catch up представляет особый интерес для изучения с позиции лингвопрагматики в связи со своей экспрессивностью и эмоциональной окраской, обусловленной ассоциациями со своим денотативным значением «играть в догонялки». Благодаря метафорическому переносу коллокация развила еще одно денотативное значение в сфере делового дискурса - «стремиться сравняться с конкурентами». Особенностью новых значений, которые закрепляются за общеупотребительными коллокациями в какойлибо специализированной сфере, является наличие выраженного коннотативного значения и экспрессивной окраски, связанной с первоначальным значением коллокации. Коллокация выполняет экспрессивную функцию.

Secondly, on value share, it's actually a very similar picture. So throughout most of last year, our market shares were bouncing around at around $40 \%$ of the business, winning. Again, we're now over $50 \%$ and actually that doesn't vary very much between the top 62 category country sales that we are laser-focused on [Technical Issues] the total state. - Bo-вторых, что касается доли рынка в денежном выражении, мы на самом деле наблюдаем очень похожую картину. Таким образом, на протяжении большей части прошлого года наши доли рынка скакали на уровне около 40 \% бизнеса, выигрывая. Опять же, сейчас мы занимаем более $50 \%$, и на самом деле это не является существенным отличием в топ-62 категории продаж в странах, где мы сосредоточены на [технические неполадки] общем состоянии.

Коллокация to bounce around имеет значения «колебаться, скакать с одного показателя на другой, однако с тенденцией к росту». К игровой сфере относится глагол to bounce, основными значениями которого являются «прыгать как мяч, отскакивать, перезапускать». В деловом английском он употребляется в значении «внезапно возрасти после спада, прийти в норму». При помощи данной коллокации автор пытается привлечь внимание к нестабильности доли рынка, отмечая, однако, выигрышные позиции бизнеса. Коллокация имеет положительное коннотативное значение - «тенденция к росту» и выполняет оценочную функцию.

On tax, Richard, I may get you to jump on, but on BoCom we do a value-in-use calculation, a DCF model of BoCom. It's not driven by the dividend payments per se, but it will be driven by what we think is sustainable cashflow out of the BoCom investment over the medium term. - Что касается налогов, Ричард, я могу вам доверить взяться за это, но в ВоСот мы делаем расчет потребительской стоимости, DCF модель ВоСот. Это обусловлено дивидендными выплатами как таковыми, но будет обусловлено тем, что мы считаем устойчивым денежным потоком от инвестищий ВоСот в среднесрочной перспективе.

В данном примере нас интересует фразовый глагол to јuтp on - «запрыгнуть, неожиданно наброситься на кого-то/что-то». В вышеуказанном контексте эта лексема имеет значение «активно взяться за дело / какое-либо занятие», сравнивая процесс прыжка с процессом выполнения задания, когда необходимо приложить максимальные усилия для достижения наилучшего результата. Благодаря метафоре из сферы-источника «игра», коллокация ассоциируется с резкостью, напористостью и внезапностью, что способствует передачи решимости. Данная коллокация выполняет экспрессивную и апеллятивную функции, так как является распоряжением. 


\section{Лексико-семантическое микрополе «движение вперед с применением грубой силы»}

В повседневной жизни коллокации, содержащие лексемы, вызывающие ассоциации с применением грубой силы, имеют отрицательные коннотации, так как ассоциируются с насилием и жестокостью. В деловом дискурсе, помимо вышеупомянутых ассоциаций, данное микрополе также передает положительные коннотации, которые выражают напористость и решимость. Рассмотрим их в следующих примерах:

Okay. Thank you, David. We've got time for one last quick question, John Ennis at Goldman Sachs. If you can make it one and make it very quick, we can squeeze it in. - Xopouo. Cnaсибо, Дэвид. У нас есть время на последний небольшой вопрос, Джон Эннис из Goldman Sachs. Если вы можете задать только один вопрос и сделать это очень быстро, мыл можем на него ответить.

Фразовый глагол to squeeze in - «втиснуть» приобрел значение «приложить усилия, чтобы найти время на что-то». Его употребление связано с интенцией автора показать, что определенное действие стоило ему больших усилий и труда, и вызвать у реципиента чувство благодарности. Коллокация to squeeze question in имеет значение «успеть задать еще один вопрос», обусловленное значением глагола to squeeze - «сильно давить, сжимать, протискивать, умещать». Употребление данной коллокации свидетельствует об интенции автора показать, что переговоры подходят к концу и что они находятся в ограниченных условиях, однако готовы приложить усилия, чтобы ответить на максимальное количество вопросов. Коннотативным значением коллокации является «прикладывать усилия». Коллокация выполняет экспрессивную и апеллятивную функции.

Yeah, I'm going to pinch a bit more on India and just say I'm very worried about the disease conditions in India. I think it's important that we think of India as WIMI, we talk about WIMI, Winning in Many Indias. - Да, я собираюсь еще немного обсудить Индию и просто сказать, что меня очень беспокоят заболевания в Индии. Я думаю, что очень важно, чтобы мы думали об Индии как о ПВМИ, мы говорим о ПВМИ, Победа во многих Индиях.

В данном примере автор употребляет фразовый глагол to pinch on, прямое значение которого - «щипать, прищемить», в значении «продолжить разговор/дискуссию/речь», что имплицитным образом сообщает слушателю/читателю, что предмет дискуссии не является приятным. Также в вышеуказанном отрывке необходимо выделить культурную аллюзию в виде цитаты призыва британского бизнесмена Санджив Мехты, стоящего во главе Unilever в Индии. Культурная аллюзия позволяет ясно и кратко донести сообщение до аудитории, а также придает речи образность и эмоциональную окраску. Коллокация to pinch on smth выполняет экспрессивную функцию.

\section{Вывод}

В результате анализа лексико-семантического поля «движение вперед» на материале англоязычных деловых встреч и совещаний было выявлено, что единицы, образующие интересующее нас ЛСП, функционируют в составе таких микрополей, как «идти», «подъем», «движение вперед с элементами игры» и «движение вперед с применением грубой силы». Употребление коллокаций, содержащих лексические единицы из метафорических сфер-источников «движение», «игра» и «грубая сила», выполняет определенные лингвопрагматические интенции, такие как отражение всего масштаба приложенных усилий, напористости и решимости; передача отношения автора к ситуации; представление деловых процессов в качестве игрового поля, на котором действуют свои правила. Все перечисленные факторы придают речи экспрессивную окраску, помогают обратить внимание читателя/слушателя на высказывание и являются инструментом создания как положительных, так и отрицательных коннотаций. 
С лексической точки зрения, большую часть коллокаций составляют фразовые глаголы, имеющие высокую степень образности и метафоричности: jump on, play out, squeeze in и др. Основной чертой фразовых глаголов является их употребление в неофициальном стиле, они создают контраст на фоне делового регистра, делая речь более экспрессивной.

Главными функциями коллокаций, входящих в ЛСП «движение вперед» являются информативная, экспрессивная, апеллятивная и оценочная. Информативную функцию выполняют все отобранные при анализе коллокации, так как они способствуют передачи информации. Второе место занимает экспрессивная функция в связи с метафорической природой коллокаций (to pinch on smth - «продолжить речь»). Апеллятивная функция широко распространена в деловом дискурсе, так как деловая речь построена на постоянном взаимодействии с реципиентом: обращение, просьба, распоряжение, вопрос и т.д. Оценочная функция обусловлена интенцией автора охарактеризовать то или иное явление, следовательно, говорящий прибегает к коллокациям, содержащим оценочный компонент: to bounce around - «скакать с одного показателя на другой, однако, с тенденцией к росту».

В ходе исследования также было выявлена тенденция к выполнению коллокациями одновременно нескольких функций: апеллятивная + экспрессивная, апеллятивная + оценочная, экспрессивная + оценочная. Наиболее частым сочетанием функций является апеллятивная + экспрессивная (to squeeze smth in, to jump on), что свидетельствует об активном использовании метафоры, антитезы и других средств создания экспрессивности при обращении к реципиенту.

\section{Список источников}

1. Edited Transcript of BP.L earnings conference call or presentation 4-Aug-20 8:00am GMT. URL: https://finance.yahoo.com/news/edited-transcript-bp-l-earnings-143834573.html (accessed: 23.03.2021).

2. HSBC Holdings plc. 2020. 3Q20 Equity Analysts meeting - Transcript, 11.04.2020. Publicnow. URL: http://docs.publicnow.com/viewDoc?filename=33584\%5CEXT\%5C18F5D14D74 FCF0F9BEF57C9200F94CCA19347AA1_0B24B488AAF6F67072B8F8A052BA23028DA608B9.PDF (accessed: 23.03.2021).

3. Motley Fool Transcribers. 2020. BP p.l.c. (BP) Q1 2020 Earnings Call Transcript. URL: https://www.fool.com/earnings/call-transcripts/2020/04/29/bp-plc-bp-q1-2020-earnings-calltranscript.aspx (accessed: 23.03.2021).

4. Unilever PLC (UL) Q2 2020 Earnings Call Transcript. 2020. By Motley Fool Transcribers, Jul 23, 2020. URL: https://www.fool.com/earnings/call-transcripts/2020/07/23/unilever-plc-ul-q2-2020earnings-call-transcript.aspx (accessed: 23.03.2021).

5. Unilever PLC (UL) Presents at CAGNY Consumer Analyst Group of New York Conference 2019 (Transcript). URL: https://seekingalpha.com/article/4243583-unilever-plc-ul-presents-cagnyconsumer-analyst-group-of-new-york-conference-2019-transcript (accessed: 23.03.2021).

\section{Список литературы}

1. Баранов А.Н., Добровольский Д.О. 2013. Основы фразеологии. М., ФЛИНТА, Наука, $312 \mathrm{c}$.

2. Белякова Н.С. 2017. Лексико-семантические поля экономических терминов (на материале англоязычного учебно-академического текста). Огарев-online, 10 (99). (Режим доступа: http://journal.mrsu.ru/arts/leksiko-semanticheskie-polya-ekonomicheskix-terminov-na-materialeangloyazychnogo-uchebno-akademicheskogo-teksta (дата обращения: 23.03.2021).

3. Ваганова А.К. 2018. Концепт "движение" как компонент национальной картины мира в рассказе А.П. Чехова "Мечты". Научная мысль Кавказа, 3 (95): 73-79. DOI: 10.18522/2072-01812018-95-3-73-79 
4. Дранко В.В. 2006. Лингвистическая прагматика и теория речевых актов как научный метод: интерпретация косвенных вопросов. Вестник Православного Свято-Тихоновского гуманитарного университета. Серия 3: Филология, 2: 191-205.

5. Малёв А.В., Мосалова А.И. 2013. Лингвопрагматический подход как методическая основа формирования профессиональной межкультурной компетенции. Русистика, 2: 114-120.

6. Малюга Е.Н. 2020. Функции юмора в англоязычном экономическом дискурсе. Вестник Московского университета. Серия 9: Филология, 6: 31-43.

7. Мартынова Ю.А. 2008. Метафора в современном политическом дискурсе. Известия Саратовского университета. Новая серия. Серия: Социология. Политология, 1: 125-129.

8. Медведева С.Н. 2019. Метафорические проекции глаголов движения в английском языке. Гипотеза, 3(8): 37-42.

9. Митина Е.А. 2010. К вопросу о структуре лексико-семантического поля «Смерть». Вестник Южно-Уральского государственного гуманитарно-педагогического университета, 12: 291-302.

10. Попова 3.Д., Стернин И.А. 2010. Лексическая система языка: внутренняя организация, категориальный аппарат и приемы описания. Москва, URSS, 171 с.

11. Сентенберг И.В. 1984. Лексическая семантика английского глагола. М., Изд-во МГПИ им. В.И. Ленина, 96 с.

12. Тамбовцева К.Д. 2014. Лексико-семантические поля молодежного американского сленга. Вестник Российского университета дружбы народов. Серия: Теория языка. Семиотика. Семантика, 3: 139-147.

13. Томалин Б., Малюга Е.Н. 2016. Деловой английский в век глобализации. Вопросы прикладной лингвистики, 24: 7-18.

14. Чудинов А.П. 2003. Метафорическая мозаика в современной политической коммуникации. Екатеринбург, Урал. гос. пед. ун-т, 248 с.

15. Crystal D. 2010. The Cambridge Encyclopedia of Language. Cambridge University Press, $524 \mathrm{p}$.

16. Alba-Juez L. 2018. Emotion and appraisal processes in language: How are they related? In Gómez González. The Construction of Discourse as Verbal Interaction. Eds. $\mathrm{M}^{\mathrm{a}}$ de los Ángeles \& J. Lachlan Mackenzie. Amsterdam, JohnBenjamins: 227-250

17. Kuzhevskaya E.B. 2019. Politeness strategies in business English discourse. Training. Language and Culture, 3(4): 36-46. DOI: 10.29366/2019tlc.3.4.4

18. Maluyga E.N., Aleksandrova O.V. 2020. Linguopragmatic aspect of idiomatic expressions in English business discourse. TILTM. European Proceedings of Social and Behavioural Sciences EpSBS. Future Academy: 1-6.

19. Malyuga E. \& McCarthy M. 2018. English and Russian vague category markers in business discourse: Linguistic identity aspects. Journal of Pragmatics, 135: 39-52. DOI: 10.1016/j.pragma.2018.07.011

20. McGee P. 2019. Cross-cultural pragmatic failure. Training, Language and Culture, 3(1): $73-$ 84. DOI: $10.29366 / 2019$ tlc.3.1.5

21. Murashova E.P. 2021. The role of the cognitive metaphor in the hybridisation of marketing and political discourses: An analysis of English-language political advertising. Training, Language and Culture, 5(2): 22-36. DOI: 10.22363/2521-442X-2021-5-2-22-36

22. Peluso M. 2021. The functional approach, semiotics and professional discourse. Training, Language and Culture, 5(2): 62-72. DOI: 10.22363/2521-442X-2021-5-2-62-72

23. Sibul V. 2017. Psycholinguistic analysis of lexical-semantic structure in linguistic consciousness of Russian, English and German native speakers. Training, Language and Culture, 1(2): 54-70. DOI: 10.29366/2017tlc.1.2.4

\section{References}

1. Baranov A.N., Dobrovol'skiy D.O. 2013. Osnovy frazeologii [Fundamentals of phraseology]. M., Publ. FLINTA, Nauka, 312 p.

2. Belyakova N.S. 2017. Lexico-semantic fields of economic terms: a study of the english academic text. Ogarev-online, 10 (99) (in Russian). URL: http://journal.mrsu.ru/arts/leksiko- 
semanticheskie-polya-ekonomicheskix-terminov-na-materiale-angloyazychnogo-uchebno-akademicheskogo teksta (accessed: 23.03.2021).

3. Vaganova A.K. 2018. The concept of "movement" as a component of national picture of the world in a.p. chekhov's story "dreams". Nauchnaya mysl' Kavkaza, 3 (95): 73-79 (in Russian). DOI: 10.18522/2072-0181-2018-95-3-73-79

4. Dranko V.V. 2006. Lingvisticheskaya pragmatika i teoriya rechevykh aktov kak nauchnyy metod: interpretatsiya kosvennykh voprosov [Linguistic pragmatics and the theory of speech acts as a scientific method: interpretation of indirect questions]. St. Tikhon's University Review. Series III: Philology, 2: 191-205.

5. Malev A.V., Mosalova A.I. 2013. Linguapragmatic approach as a methodological basis for professional intercultural competence development. Russian language studies, 2: 114-120 (in Russian).

6. Malyuga E.N. 2020. Functions of humour in spoken english economic discourse. Moscow University Philology Bulletin, 6: 31-43 (in Russian).

7. Martynova Yu.A. 2008. Metaphor in Msderm Political Discourse. Izvestia of saratov university. New series. Series: sociology. Politology, 1: 125-129 (in Russian).

8. Medvedeva S.N. 2019. Metaphorical projections of english motion verbs. Hypothesis, 3: $37-$ 42 (in Russian).

9. Mitina E.A. 2010. Revisited the structure of "death" lexical-and-semantic field. Vestnik Yuzhno-Ural'skogo gosudarstvennogo gumanitarno-pedagogicheskogo universiteta, 12: 291-302 (in Russian).

10. Popova Z.D., Sternin I.A. 2010. Leksicheskaya sistema yazyka: vnutrennyaya organizatsiya, kategorial'nyy apparat i priemy opisaniya [Lexical system of language: internal organization, categorical apparatus and methods of description]. M., Publ. URSS, $171 \mathrm{p}$.

11. Sentenberg I.V. 1984. Leksicheskaya semantika angliyskogo glagola [Lexical system of language: internal organization, categorical apparatus and methods of description]. M., Publ. MGPI im. V.I. Lenina, 96 p.

12. Tambovtseva K.D. 2014. Lexico-semantic field of american youth slang. RUDN journal of language studies, semiotics and semantics, 3: 139-147 (in Russian).

13. Tomalin B., Malyuga E.N. 2016. Business english in the global age. Voprosy prikladnoy lingvistiki, 24: 7-18 (in Russian).

14. Chudinov A.P. 2003. Metaforicheskaya mozaika v sovremennoy politicheskoy kommunikatsii [Metaphorical mosaic in modern political communication. Ekaterinburg, Publ. Ural. gos. ped. un-t, 248 p.

$524 \mathrm{p}$.

15. Crystal D. 2010. The Cambridge Encyclopedia of Language. Cambridge University Press,

16. Alba-Juez L. 2018. Emotion and appraisal processes in language: How are they related? In Gómez González. The Construction of Discourse as Verbal Interaction. Eds. $\mathrm{M}^{\mathrm{a}}$ de los Ángeles \& J. Lachlan Mackenzie. Amsterdam, JohnBenjamins: 227-250.

17. Kuzhevskaya E.B. 2019. Politeness strategies in business English discourse. Training. Language and Culture, 3(4): 36-46. DOI: 10.29366/2019tlc.3.4.4

18. Maluyga E.N., Aleksandrova O.V. 2020. Linguopragmatic aspect of idiomatic expressions in English business discourse. TILTM. European Proceedings of Social and Behavioural Sciences EpSBS. Future Academy: $1-6$.

19. Malyuga E. \& McCarthy M. 2018. English and Russian vague category markers in business discourse: Linguistic identity aspects. Journal of Pragmatics, 135: 39-52. DOI: 10.1016/j.pragma.2018.07.011

20. McGee P. 2019. Cross-cultural pragmatic failure. Training, Language and Culture, 3(1): $73-$ 84. DOI: $10.29366 / 2019$ tlc.3.1.5

21. Murashova E.P. 2021. The role of the cognitive metaphor in the hybridisation of marketing and political discourses: An analysis of English-language political advertising. Training, Language and Culture, 5(2): 22-36. DOI: 10.22363/2521-442X-2021-5-2-22-36

22. Peluso M. 2021. The functional approach, semiotics and professional discourse. Training, Language and Culture, 5(2): 62-72. DOI: 10.22363/2521-442X-2021-5-2-62-72 
23. Sibul V. 2017. Psycholinguistic analysis of lexical-semantic structure in linguistic consciousness of Russian, English and German native speakers. Training, Language and Culture, 1(2): 54-70. DOI: $10.29366 / 2017$ tlc.1.2.4

Конфликт интересов: о потенциальном конфликте интересов не сообщалось.

Conflict of interest: no potential conflict of interest related to this article was reported.

\section{ИНФОРМАЦИЯ ОБ АВТОРЕ}

Мадинян Елена Игоревна, ассистент кафедры иностранных языков экономического факультета Российского университета дружбы народов, г. Москва, Россия

\section{INFORMATION ABOUT THE AUTHOR}

Elena I. Madinyan, Assistant, Department of Foreign Languages, Faculty of Economics, Peoples' Friendship University of Russia, Moscow, Russia 